\title{
Adenoid Cystic Carcinoma Metastasized to Colon
}

\author{
Patricia Guzman Rojas ${ }^{1}$, Jignesh Parikh ${ }^{2}$, Priya Vishnubhotla ${ }^{3}$, Jeannette Vergeli-Rojas ${ }^{4}$ \\ 1. Internal Medicine, UCF College of Medicine 2. Pathology, Orlando VA Medical Center 3. Medicine, \\ Hematology-Oncology, Orlando VA Medical Center 4. Gastroenterology, Orlando VA Medical Center
}

$\square$ Corresponding author: Patricia Guzman Rojas, patricia.guzman@upch.pe

Disclosures can be found in Additional Information at the end of the article

\section{Abstract}

Adenoid cystic carcinoma (ACC) is an infrequent cause of malignancy that accounts for $1 \%$ of all tumors of the oral and maxillofacial region.

We present a 59-year-old woman with a past medical history of adenoid cystic carcinoma of the left salivary gland treated with radiation and thoracotomy due to lung metastasis. Years after the onset of diagnosis, she presented with nonspecific gastrointestinal symptoms. For this reason, an abdominal computed tomography (CT) scan was done, revealing a liver mass in the right lobe, involving segments eight and five, concerning for malignancy. A colonoscopy was indicated for screening purposes, showing a large polyp that was biopsied. A histopathologic examination of the colon polyp and a liver biopsy was compatible with ACC metastatic carcinoma.

We report this case to highlight an unusual location of metastatic ACC. Furthermore, there is no case report in the literature where colon metastasis has been described.

Received 11/17/2017

Review began 12/13/2017

Review ended 01/17/2018

Published 01/18/2018

C) Copyright 2018

Guzman Rojas et al. This is an open access article distributed under the terms of the Creative Commons Attribution License CC-BY 3.0., which permits unrestricted use, distribution, and reproduction in any medium, provided the original author and source are credited.
Categories: Gastroenterology, Oncology

Keywords: adenoid cystic carcinoma, liver metastases, colon, lung mass

\section{Introduction}

Adenoid cystic carcinoma (ACC) is an infrequent cause of malignancy, accounting for $1 \%$ of all tumors from the oral and maxillofacial region [1]. It is known that this type of malignancy can arise from any mucous gland from the hard palate, tongue, and other areas [2].

\section{Case Presentation}

We present a 59-year-old woman with a past medical history of adenoid cystic carcinoma of the left salivary gland treated with surgery followed by radiation. Seven years later, the patient underwent an osteoradionecrosis and mandibulectomy with reconstruction. At that time, a staging computed tomography (CT) scan that showed bilateral lung metastasis with a biopsy and a confirmatory diagnosis of adenoid cystic carcinoma of the lung. Therefore, she underwent a bilateral thoracotomy, without radiation or chemotherapy.

Years after this diagnosis, she presented to urgent care with nonspecific symptoms of nausea, vomiting, and diarrhea. During the evaluation, a CT scan was done, which revealed a liver mass (Figure 1). A magnetic resonance imaging (MRI) scan confirmed an 11-cm mass in the right lobe, involving segments eight and five, concerning for malignancy. An upper endoscopy 


\section{Cureus}

(EGD)/colonoscopy was scheduled as clearance prior to possible partial hepatectomy. The EGD showed no abnormalities; however, the colonoscopy showed a large, 1.2-1.5 cm hard, sessile polyp at $45 \mathrm{~cm}$ from the anus (Figure 2). No other major abnormalities were found. A histopathologic examination of the colonic polyp and a liver biopsy were compatible with metastatic carcinoma (Figure 3). The colonic tumor showed areas of classic ACC; however, the liver tumor did not have the fully developed typical morphology of ACC.

Immunohistochemical studies for CK7, SOX-10, p63, S100, BCL2, and CD117 were consistent with metastatic ACC in both colon and liver tumors. After the diagnosis of metastatic ACC, the patient was referred to oncology for palliative treatment. Furthermore, the patient declined any further therapy and was established with hospice care.

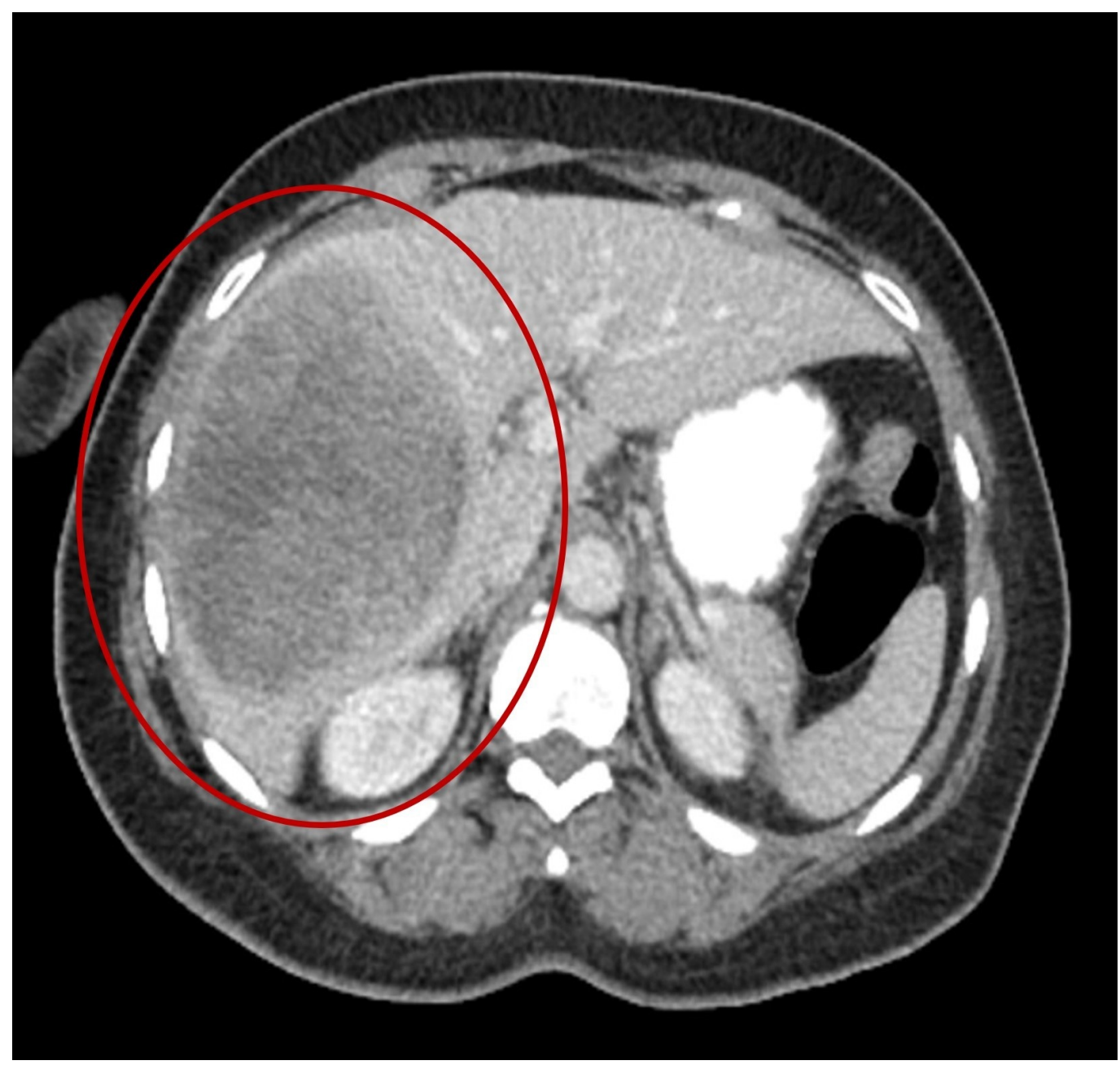

FIGURE 1: CT of the abdomen: $11 \mathrm{~cm}$ mass in the right lobe.

CT: computed tomography 


\section{Cureus}

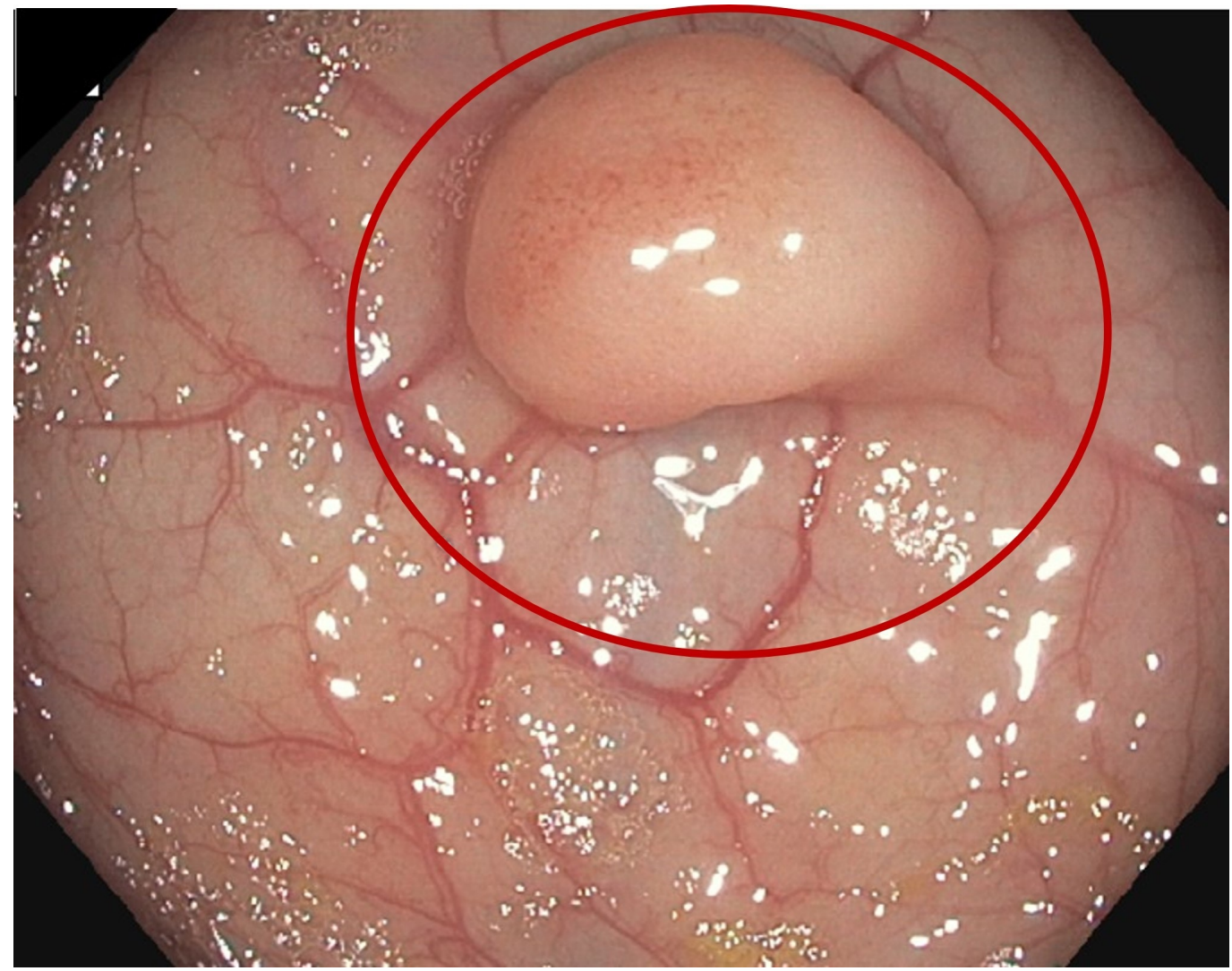

FIGURE 2: Colonoscopy: $1.2-1.5 \mathrm{~cm}$ polyp found at $45 \mathrm{~cm}$ from the anus.

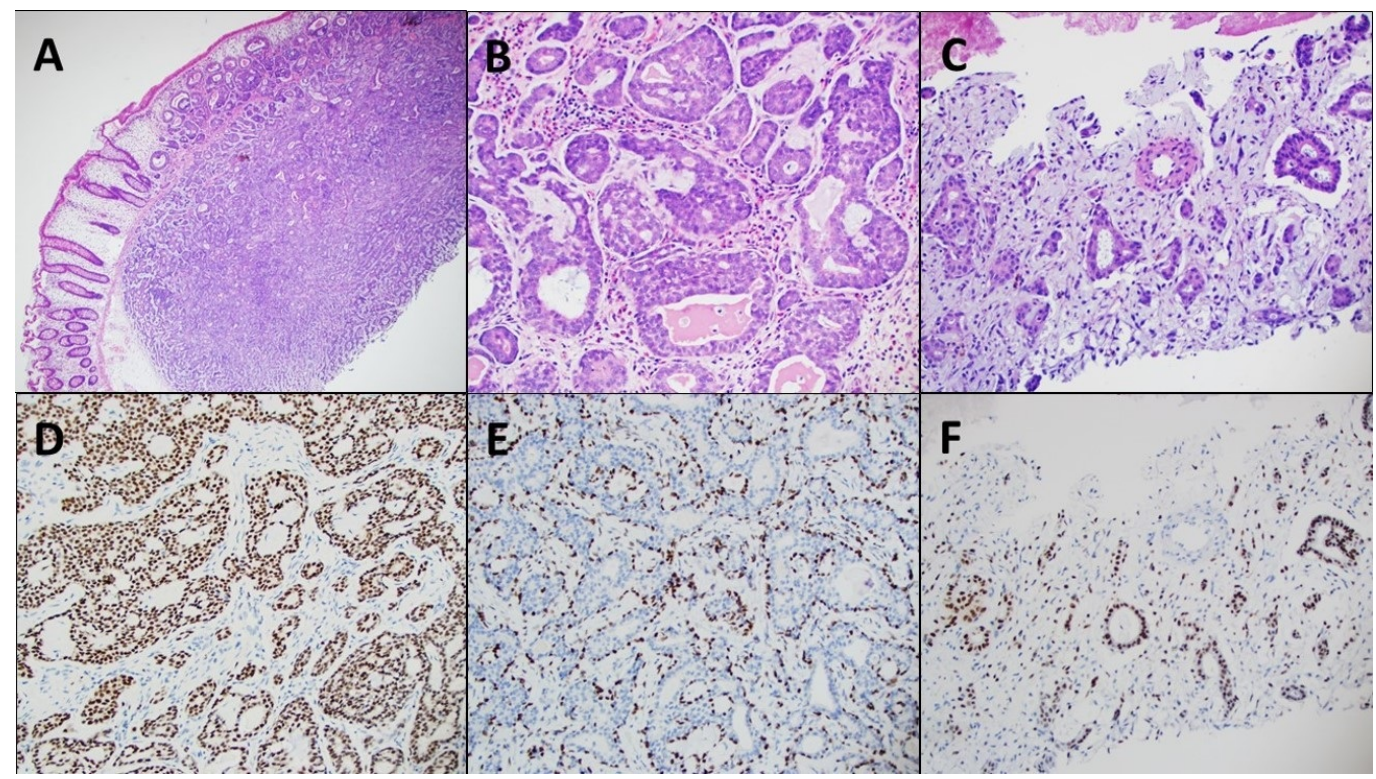

FIGURE 3: Hematoxylin and eosin stained sections show the area of metastatic carcinoma in colonic ( $A$ and $B$ ) and liver biopsies (Figure $C$ ). Areas of classic ACC are seen in the colonic biopsy (Figure B). SOX 10 is expressed both in luminal and abluminal cells (Figure E, colon; Figure G, liver). P63 


\section{Discussion}

Salivary gland carcinoma is a rare malignancy that has multiple histological subtypes, with ACC making up only $10 \%$ of them [3]. Even though the progression of ACC is slow, it has a poor outcome. Furthermore, it is already established that this malignancy has frequent recurrences and a late onset distant metastasis. The organs most frequently involved are the lungs, bones, brain, and liver. The most commonly involved intraoral site is the palate, but this could also arise from the tongue [2].

As was stated by Gondivkar, et al., the epidemiology of this malignancy shows an increased frequency in women in the fifth and sixth decades of life; moreover, it is rarely found in the population younger than 20 years old [2]. The histopathology of this type of cancer represents a mixture of myoepithelial and ductal cells [2]. There are three characteristics patterns: cribriform, tubular, and solid.

The treatment is based on surgery, radiotherapy, chemotherapy, and combined therapy. Early surgical intervention is the preferred modality for localized ACC; however, a strategy to prevent relapses is adding radiotherapy [1]. Nonetheless, the presence of distant metastases incentivizes a palliative approach, with radiation and/or adjuvant chemotherapy. Conventional chemotherapy regimens, such as cisplatin and fluorouracil (5-FU) or cisplatin, doxorubicin, cyclophosphamide (CAP), are still the first-line therapy.

As is expected, the literature describes an advanced tumor stage as a poor prognostic factor; nevertheless, some authors identify the histological subtype (trabecular and solid) as a high degree of malignancy [4-5]. Particularly, these subtypes have been associated with recurrences and early distant metastasis.

According to the NCCN guidelines [6], surveillance is based on histoy and physical every one to three months, during the first year; every two to six months during the second year; every four to eight months during years three and five and every 12 months after the first five years. Routine annual imaging can be indicated in areas difficult to visualize on exam. It is important to mention, that the only recommended distant imaging is a chest CT in patients with smoking history.

There are few case reports where patients with ACC present with metastasis to the liver [79]; however, there is no literature yet on cases where a metastasis is found in the colon. On the other hand, Harish et al. [7] reported a patient that presented metastasis even after a surgical excision was done, like ours.

\section{Conclusions}

We report this case to highlight an unusual location of metastatic ACC. Furthermore, there is no case report in the literature where colon metastasis has been described. We would like physicians to be aware of the possibility of distant and late metastases of this type of malignancy.

\section{Additional Information}




\section{Disclosures}

Human subjects: Consent was obtained by all participants in this study. Conflicts of interest: In compliance with the ICMJE uniform disclosure form, all authors declare the following:

Payment/services info: All authors have declared that no financial support was received from any organization for the submitted work. Financial relationships: All authors have declared that they have no financial relationships at present or within the previous three years with any organizations that might have an interest in the submitted work. Other relationships: All authors have declared that there are no other relationships or activities that could appear to have influenced the submitted work.

\section{References}

1. Kokemueller H, Eckardt A, Brachvogel P, Hausamen JE: Adenoid cystic carcinoma of the head and neck - a 20 years experience. Int J Oral Maxillofac Surg. 2004, 33:25-31. 10.1054/ijom.2003.0448

2. Gondivkar SM, Gadbail AR, Chole R, Parikh RV: Adenoid cystic carcinoma: a rare clinical entity and literature review. Oral Oncol. 2011, 47:231-236.

10.1016/j.oraloncology.2011.01.009

3. Matsuba HM, Spector GJ, Thawley SE, Simpson JR, Mauney M, Pikul FJ: Adenoid cystic salivary gland carcinoma: a histopathologic review of treatment failure patterns. Cancer. 1986, 57:519-524. 10.1002/1097-0142(19860201)57:3<519::AID-CNCR2820570319>3.0.CO;2$\mathrm{V}$

4. Perzin KH, Gullane P, Clairmont AC: Adenoid cystic carcinomas arising in salivary glands: a correlation of histologic features and clinical course. Cancer. 1978, 1978:265-282.

10.1002/1097-0142(197807)42:1<265::AID-CNCR2820420141>3.0.CO;2-Z

5. Szanto PA, Luna MA, Tortoledo ME, White RA: Histologic grading of adenoid cystic carcinoma of the salivary glands. Cancer. 1984, 54:1062-1069. 10.1002/10970142(19840915)54:6<1062::AID-CNCR2820540622>3.0.CO;2-E

6. National Comprehensive Cancer Network. (2017). Accessed: 1/2/18: https://www.nccn.org/professionals/physician_gls/pdf/head-and-neck.pdf.

7. Harish K, Gouri SRM: Adenoid cystic carcinoma of the parotid metastasizing to the liver: case report. BMC Cancer. 2004, 4:41. 10.1186/1471-2407-4-41

8. Spolverato G, Fite J, Bishop J, Argani P, Pawlik TM: Liver metastasis as the initial presentation of adenoid cystic carcinoma. Dig Dis Sci. 2014, 59:2004-2006. 10.1007/s10620-014-3078-6

9. Deshpande AH, Kelkar AA: Hepatic metastasis as an initial manifestation of salivary adenoid cystic carcinoma: cytologic diagnosis. Diagn Cytopathol. 2009, 37:45-47. 10.1002/dc.20961 